\title{
Lead quantitation challenge
}

\section{Enea Pagliano ${ }^{1}$}

Published online: 3 April 2019

(C) Her Majesty the Queen in Right of Canada 2019 as represented by NRC Canada 2019

We would like to invite you to participate in the Analytical Challenge, a series of puzzles to entertain and challenge our readers. This special feature of "Analytical and Bioanalytical Chemistry" has established itself as a truly unique quiz series, with a new scientific puzzle published every three months. Readers can access the complete collection of published problems with their solutions on the $A B C$ homepage at http://www.springer.com/abc. Test your knowledge and tease your wits in diverse areas of analytical and bioanalytical chemistry by viewing this collection.

In the present challenge, lead quantitation is the topic. And please note that there is a prize to be won (a Springer book of your choice up to a value of $€ 100$ ). Please read on...

\section{Meet the challenge}

The discovery of lead belongs to the accounts of ancient history. This heavy metal was known to Egyptians, Hebrews, Phoenicians, Greeks, and Romans, who used it and already had some understanding of its toxicity [1-3]. Lead poisoning has been related to several symptoms, which include neurological and behavioral effects, abdominal pain, anemia, arthritis, and damage to kidneys [1,2]. Across history, numerous examples of widespread plumbism have been documented. In the Roman Empire, lead cookware and utensils were common and lead acetate was used as a sweetener for food and wine. As a result, the average daily intake of lead for Roman aristocrats was well above those of the lower class [1]. In fact, the widespread occurrence of saturnine gout in Roman aristocrats has

Enea Pagliano

enea.pagliano@nrc-cnrc.gc.ca; enea.pagliano@outlook.com

1 National Research Council Canada, 1200 Montreal Road, K1A 0R6, Ottawa, ON Canada led some scholars to suggest that lead poisoning played an important role in the fall of the Roman Empire [1]. Another epidemic of gout affected England during the 18th century and is related to lead content in wines [1, 3]. Closer to our days, the use of lead paints in housing and tetraethyl lead in gasoline has contributed to large-scale pediatric lead poisoning for most of the 20th century [2]. The severity of lead poisoning has gained the attention of many regulatory bodies and led to the establishment of safe exposure limits in order to prevent toxic effects of lead [2]. As an example, lead content in drinking water is now widely regulated worldwide and Canadian standards allow a maximum acceptable concentration of $5 \mu \mathrm{g} / \mathrm{l}[4]$.

\section{The challenge}

At the very low concentration of $5 \mu \mathrm{g} / \mathrm{l}$, robust quantitation of lead is generally achieved by inductively coupled plasma mass spectrometry (ICPMS). As shown in Fig. 1, lead consists of four stable isotopes. As the most abundant isotopes, lead-206, lead-207, and lead-208 are usually employed for sensitive quantitation of lead by ICPMS.

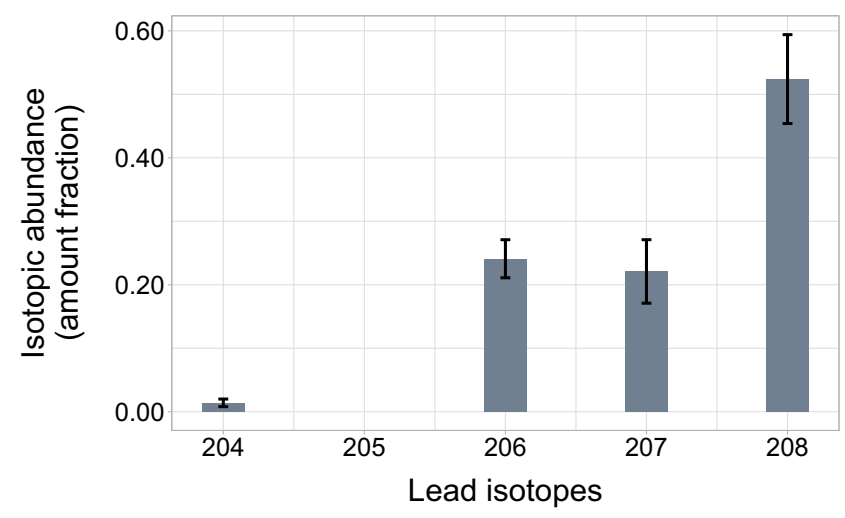

Fig. 1 Isotopic composition of lead: amount fraction of its isotopes and their natural variations in common lead [5] 
Table 1 Determination of lead in a synthetic drinking water sample by two laboratories ${ }^{a}$

\begin{tabular}{|c|c|c|c|c|c|c|c|}
\hline $\begin{array}{l}\text { Lab. } 1 \\
w(\mathrm{~Pb})\end{array}$ & ${ }^{206} \mathrm{~Pb}$ & ${ }^{207} \mathrm{~Pb}$ & ${ }^{208} \mathrm{~Pb}$ & $\begin{array}{l}\text { Lab. } 2 \\
w(\mathrm{~Pb})\end{array}$ & ${ }^{206} \mathrm{~Pb}$ & ${ }^{207} \mathrm{~Pb}$ & ${ }^{208} \mathrm{~Pb}$ \\
\hline 0.00 & 0 & 0 & 0 & 0.00 & 0 & 0 & 0 \\
\hline 0.95 & 378 & 326 & 796 & 1.20 & 455 & 342 & 861 \\
\hline 2.50 & 994 & 857 & 2094 & 3.00 & 1138 & 855 & 2153 \\
\hline 3.40 & 1352 & 1165 & 2848 & 5.20 & 1973 & 1482 & 3733 \\
\hline 5.90 & 2346 & 2022 & 4942 & 8.30 & 3149 & 2365 & 5958 \\
\hline 7.20 & 2863 & 2468 & 6031 & 11.0 & 4173 & 3134 & 7896 \\
\hline Sample & 1861 & 1748 & 4117 & Sample & 1629 & 1530 & 3603 \\
\hline
\end{tabular}

${ }^{\mathrm{a}} w(\mathrm{~Pb})$ is the mass fraction of lead in the calibration standards $(\mu \mathrm{g} / \mathrm{l}) .{ }^{206} \mathrm{~Pb},{ }^{207} \mathrm{~Pb},{ }^{208} \mathrm{~Pb}$ are the ICPMS signals measured at $m / z$ of 206,207 and 208

As part of a quality assurance program, a synthetic drinking water sample (A) was sent for lead analysis to two laboratories. In both cases, three lead isotope signals (lead206, lead-207, and lead-208) were used for quantitation and quality control purposes. The calibration curve was prepared by analysis of available aqueous lead standard solutions and was used to determine the mass fraction of lead in the drinking water sample $\mathrm{A}, w(\mathrm{~Pb})_{A}$. Table 1 contains all measurement data reported by the two testing laboratories.

Laboratory 1 reported the following results:

$$
\begin{aligned}
& { }^{206} \mathrm{~Pb}: w(\mathrm{~Pb})_{\mathrm{A}}=4.7 \mu \mathrm{g} / 1 \\
& { }^{207} \mathrm{~Pb}: w(\mathrm{~Pb})_{\mathrm{A}}=5.1 \mu \mathrm{g} / 1 \\
& { }^{208} \mathrm{~Pb}: w(\mathrm{~Pb})_{\mathrm{A}}=4.9 \mu \mathrm{g} / 1
\end{aligned}
$$

Laboratory 2 reported the following results:

$$
\begin{aligned}
& { }^{206} \mathrm{~Pb}: w(\mathrm{~Pb})_{\mathrm{A}}=4.3 \mu \mathrm{g} / 1 \\
& { }^{207} \mathrm{~Pb}: w(\mathrm{~Pb})_{\mathrm{A}}=5.4 \mu \mathrm{g} / 1 \\
& { }^{208} \mathrm{~Pb}: w(\mathrm{~Pb})_{\mathrm{A}}=5.0 \mu \mathrm{g} / 1
\end{aligned}
$$

Despite the absence of outliers or spectral interferences, a large disagreement between the results was observed with values ranging from $4.3 \mu \mathrm{g} / \mathrm{l} \mathrm{Pb}$ to $5.4 \mu \mathrm{g} / \mathrm{l} \mathrm{Pb}$. Notably, neither of the laboratories were able to determine if the lead levels in the water sample are above or below $5 \mu \mathrm{g} / \mathrm{l} \mathrm{Pb}$ [4].

Can you provide reasons for the disagreement between the lead concentrations reported by these laboratories?
Publisher's note Springer Nature remains neutral with regard to jurisdictional claims in published maps and institutional affiliations.

\section{References}

1. Nriagu JO. Saturnine gout among Roman aristocrats-did lead poisoning contribute to the fall of the empire? $\mathrm{N}$ Engl J Med. 1983;308:660-663. https://doi.org/10.1056/nejm198303173081123.

2. Hernberg S. Lead poisoning in a historical perspective. Am J Ind Med. 2000;38:244-254. https://doi.org/10.1002/1097-0274(2000 09)38:3<244::aid-ajim3 > 3.0.co;2-f.

3. Montes-Santiago J. The lead-poisoned genius: Saturnism in famous artists across five centuries. 203:223-240. https://doi.org/10.1016/ b978-0-444-62730-8.00009-8. 2013.

4. Federal-Provincial-Territorial committee on drinking water, Lead in drinking water, Health Canada 2017.

5. Meija J, Coplen TB, Berglund M, Brand WA, De Bièvre $P$, Gröning $\mathrm{M}$, Holden NE, Irrgeher J, Loss RD, Walczyk T, Prohaska T. Isotopic compositions of the elements 2013 (IUPAC Technical Report). Pure Appl Chem. 2016;88:293-306. https://doi. org/10.1515/pac-2015-0503.

We invite our readers to participate in the Analytical Challenge by solving the puzzle above. Please send the correct solution to abc-challenge@springer.com by July 1, 2019. Make sure you enter "Lead quantitation challenge" in the subject line of your e-mail. The winner will be notified by e-mail and his/her name will be published on the "Analytical and Bioanalytical Chemistry" homepage at http://www.springer.com/abc and in the journal (volume 411/issue25) where readers will find the solution and a short explanation.

The next Analytical Challenge will be published in 411/17, July 2019. If you have enjoyed solving this Analytical Challenge you are invited to try the previous puzzles on the ABC homepage. 